\title{
Stabilizer-Free Dispersion Copolymerization Monitoring by In-Line NIR Spectroscopy
}

Maria G. F. Torraga*, Reinaldo Giudici

Universidade de São Paulo

Escola Politécnica

Department of Chemical Engineering

Av. Prof. Luciano Gualberto travessa 3, no. 380

Cidade Universitária 05508-010 São Paulo, SP, Brazil 

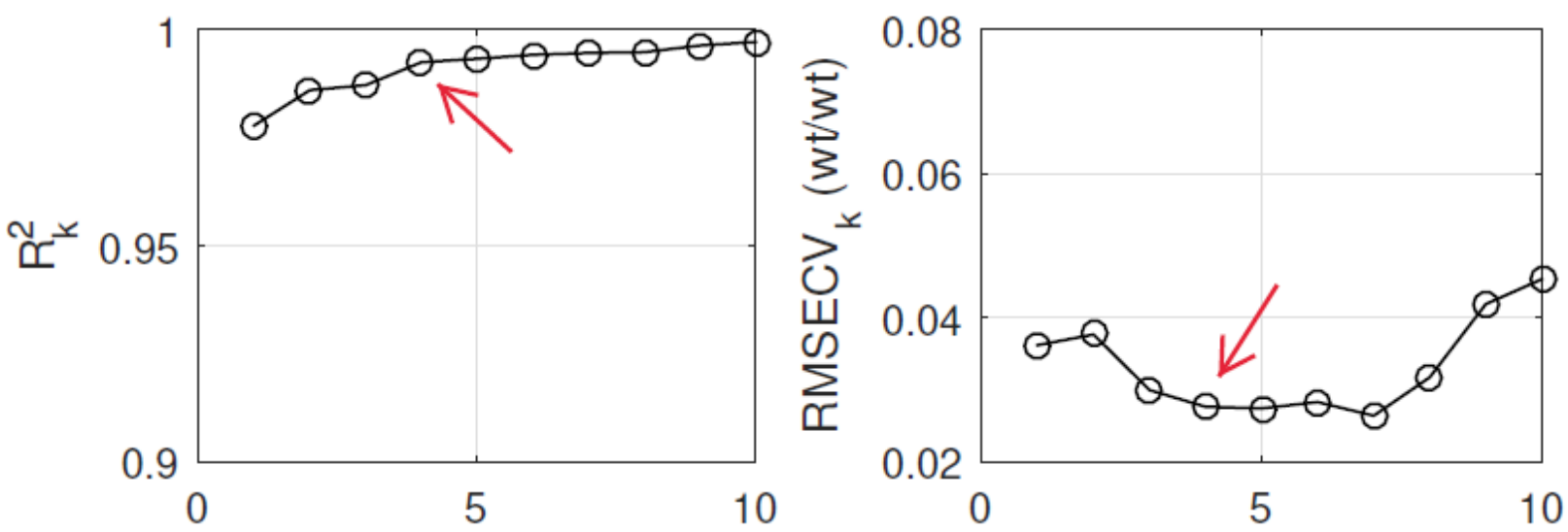

Number of PLS components $\mathrm{k}$
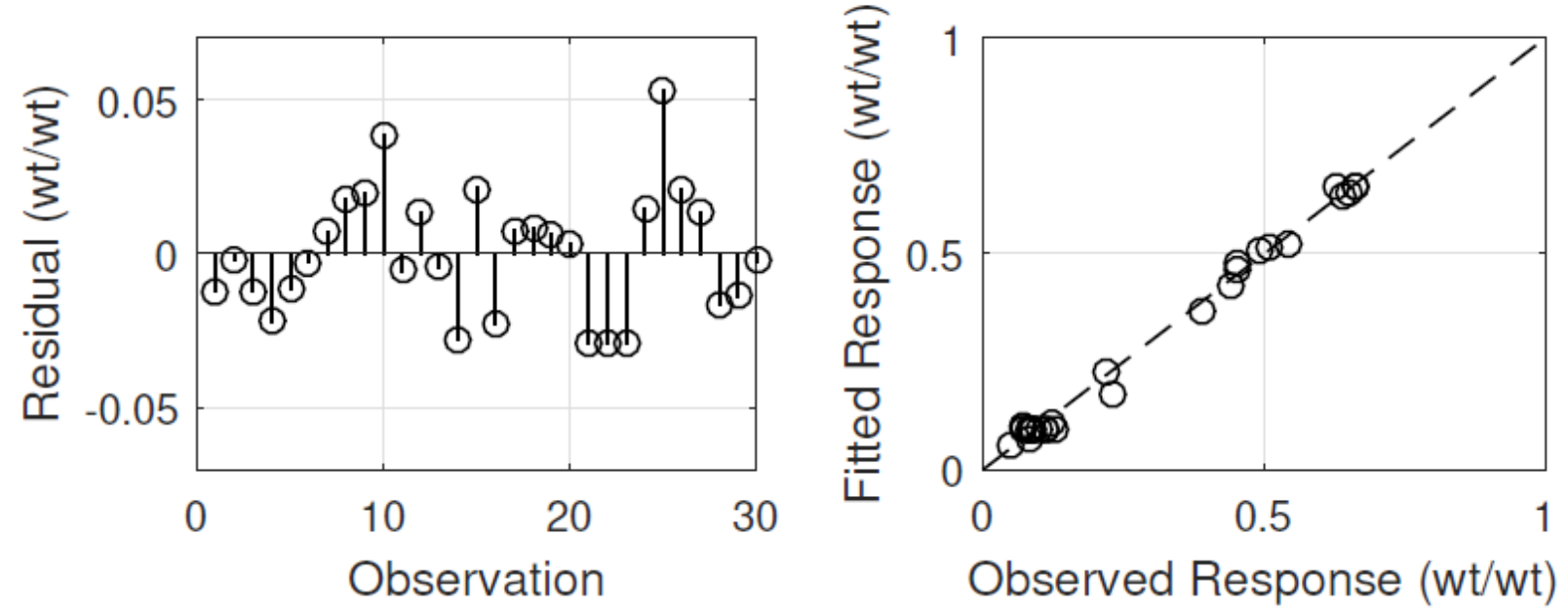

Figure S1. Selection criteria $\left(R^{2}\right.$ and $\left.R M S E C V\right)$, residuals plot and parity graph for model X2. 

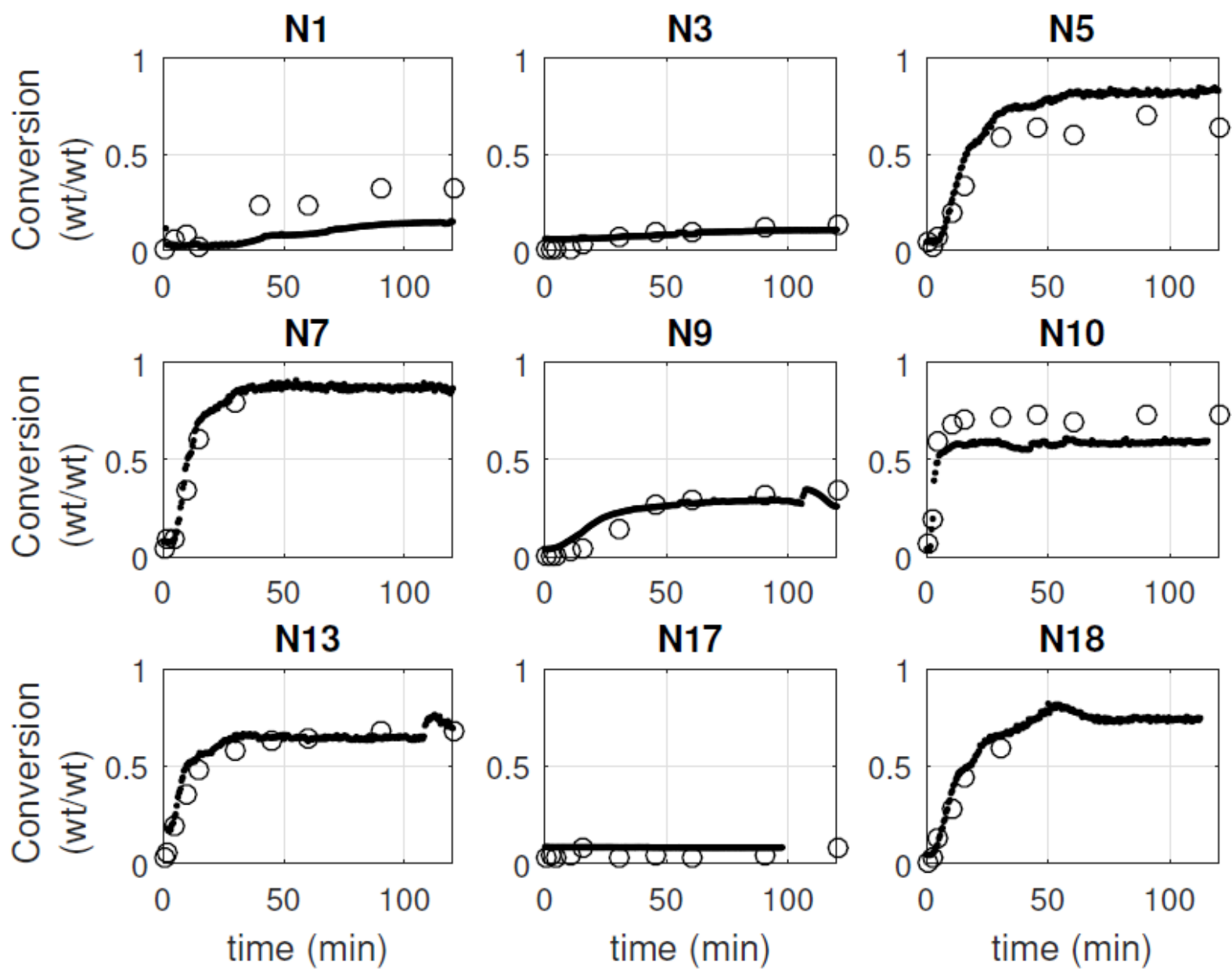

Figure S2. External validation of global conversion model X2 (6500-5400 $\left.\mathrm{cm}^{-1}\right)$. Experimental data (o); NIR model prediction $(\bullet)$. 


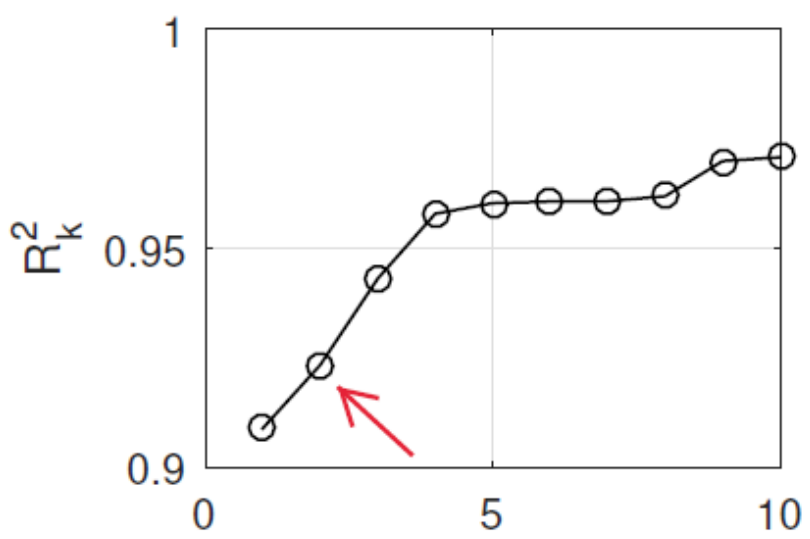

Number of PLS components $\mathrm{k}$

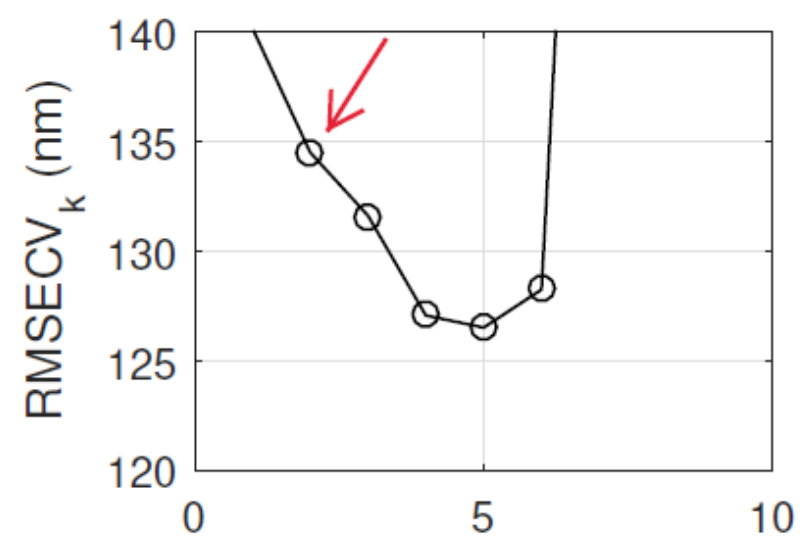

Number of PLS components $\mathrm{k}$
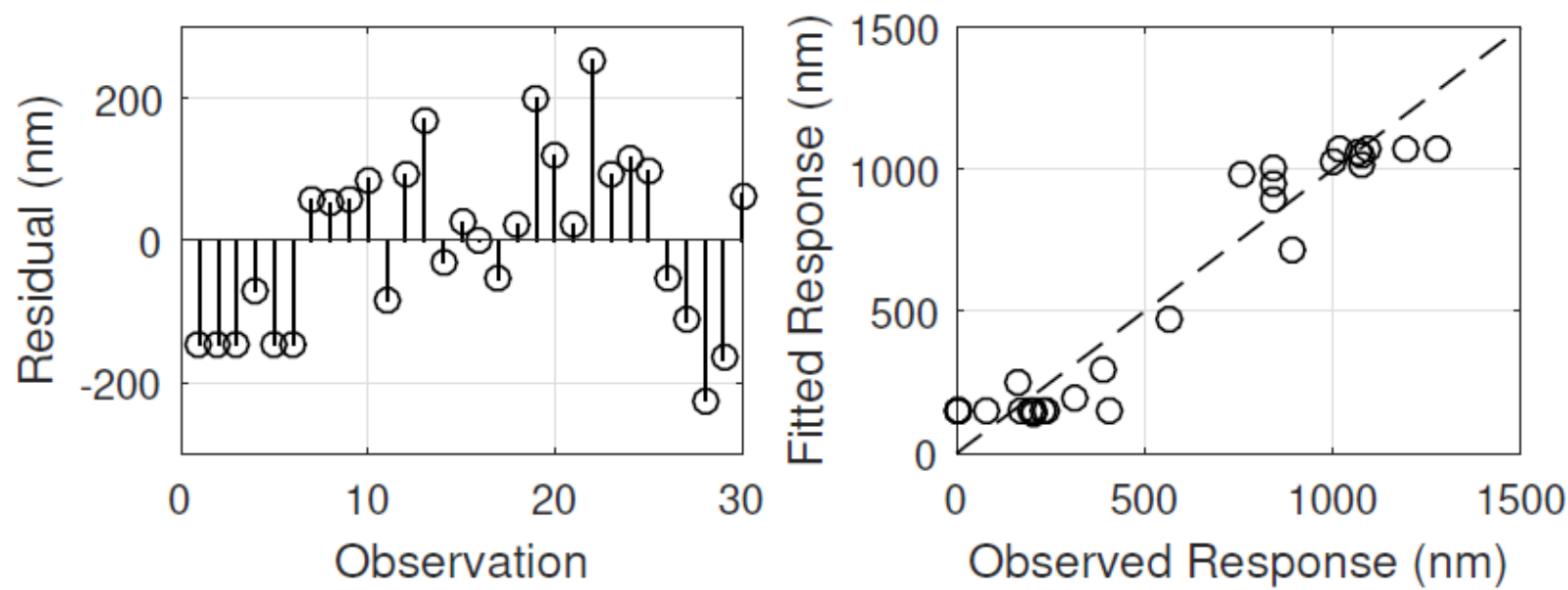

Figure S3. Selection criteria $\left(R^{2}\right.$ and $\left.R M S E C V\right)$, residuals plot and parity graph for model D2. 

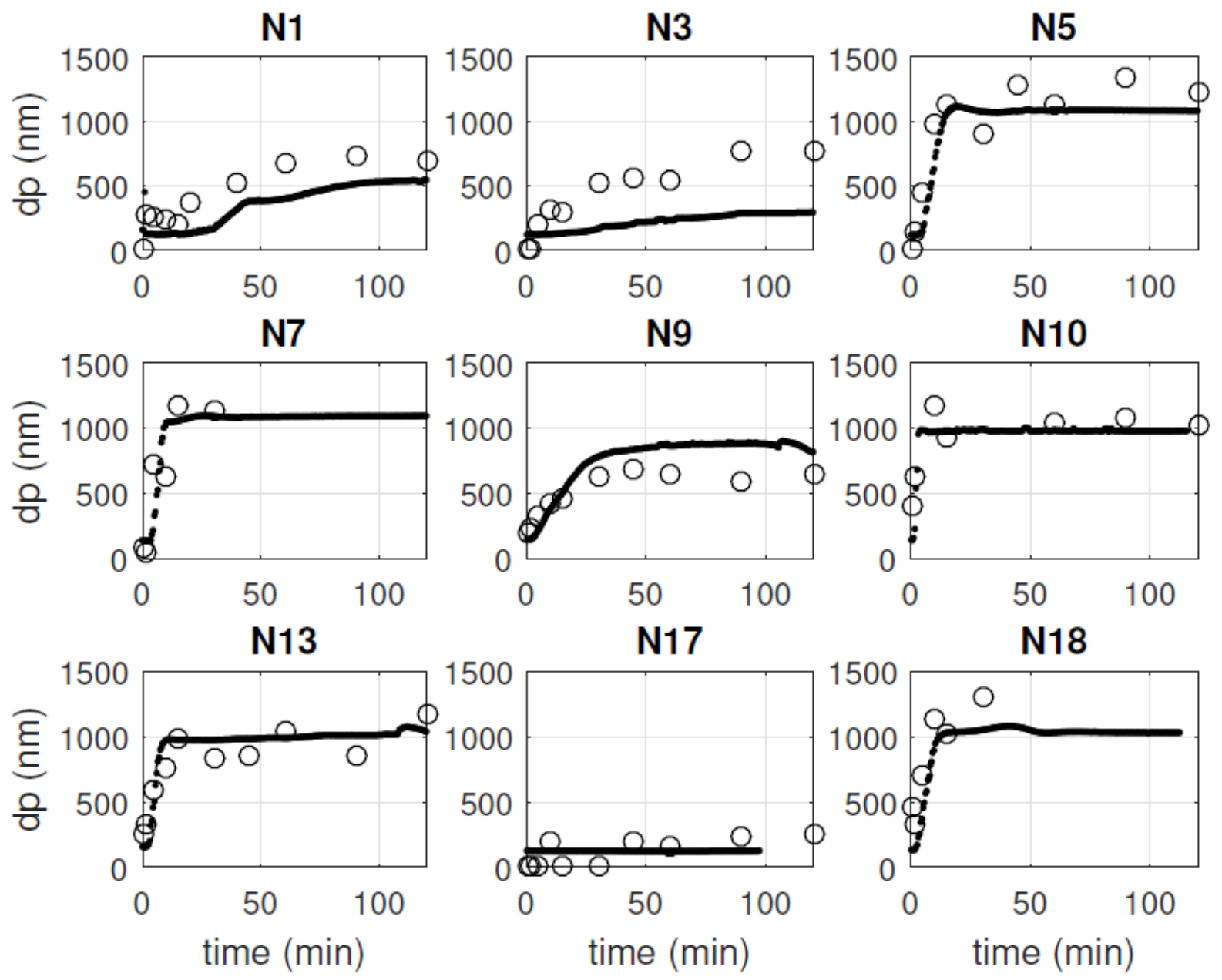

Figure S4. External validation of particle size model D2 $\left(14000-6500 \mathrm{~cm}^{-1}\right)$. Experimental data $(\mathrm{o})$; NIR model prediction $(\bullet)$. 